\title{
Micro-abrasion-corrosion Maps of 316L Stainless Steel in Artificial Saliva
}

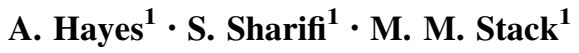

Received: 22 October 2014/Revised: 2 March 2015/Accepted: 1 April 2015/Published online: 18 April 2015

(C) Springer International Publishing AG 2015

\begin{abstract}
The role of salivary media is essential during mastication and ingestion processes; yet it can hinder the performance of foreign materials in the oral cavity. The aim of this study was to examine the effects of applied load and applied electrical potential on the tribo-corrosion mechanisms of $316 \mathrm{~L}$ stainless steel in an environment similar to oral cavity conditions. $316 \mathrm{~L}$ stainless steel is a material commonly used in dentistry for orthodontic braces, wires and in some cases as dental crowns. This is due to its favourable corrosion resistance. Relatively few studies have examined the materials performance in an oral environment. The results of this work were used to generate polarisation curves and wastage and mechanism maps to describe the material's tribo-corrosion behaviour. A significant difference in corrosion current densities was observed in the presence of abrasive particles suggesting the removal of the protective chromium oxide passive film. It was found that the corrosion resistant nature of $316 \mathrm{~L}$ stainless steel resulted in a wear mechanism which was micro-abrasion dominated for all test conditions.
\end{abstract}

Keywords $316 \mathrm{~L}$ stainless steel $\cdot$ Artificial saliva $\cdot$ Oral cavity $\cdot$ Abrasion $\cdot$ Corrosion $\cdot$ Tribo-corrosion mechanisms

\section{List of symbols}

A Surface area of wear scar $\left(\mathrm{m}^{2}\right)$

$a \quad$ Radius of wear scar (m)

M. M. Stack

Margaret.stack@strath.ac.uk

1 Department of Mechanical and Aerospace Engineering, University of Strathclyde, Glasgow, UK

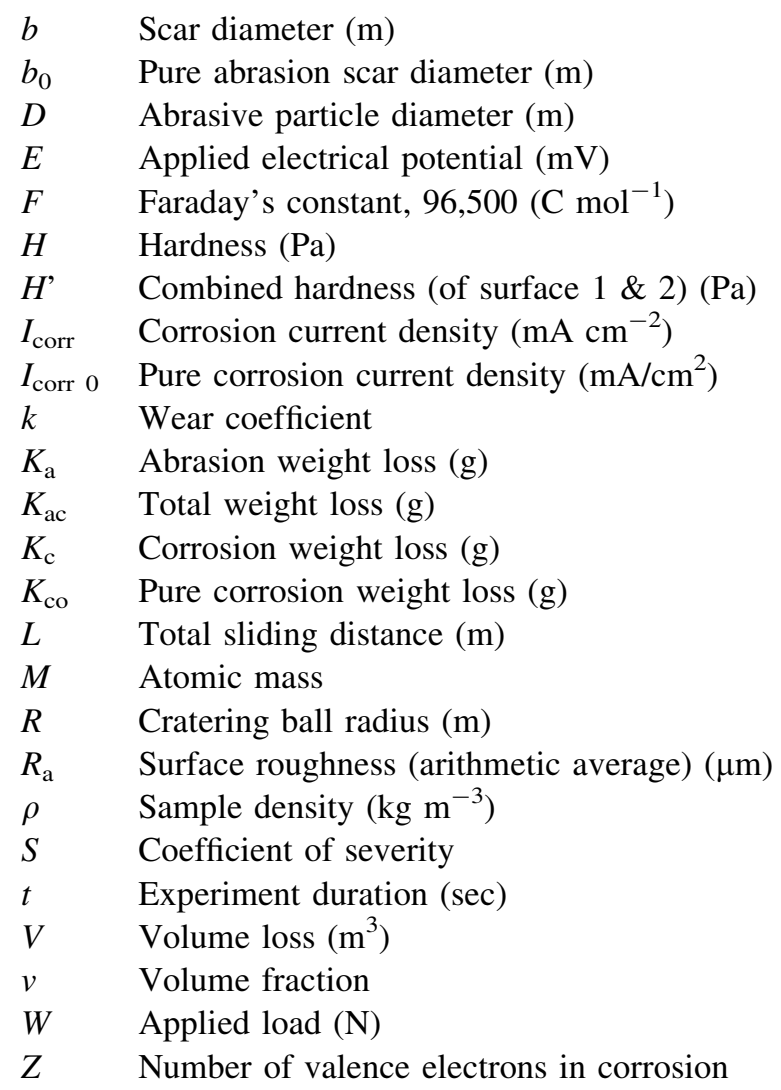

\section{Introduction}

The oral cavity represents a significantly challenging environment in materials science. One of the main existing elements in the oral cavity, which can sometimes be overlooked by the material scientists, is saliva and its 
important roles. During the mastication and ingestion processes, the role of salivary media is multi-faceted, i.e. saliva functions as a taste compound diffuser, a lubricant for oral surfaces, a biochemical agent for food structure and an essential ingredient for bolus formation and safe ingestion [1]. The surfaces in the oral cavity can compromise of foreign materials, such as dental replacement and orthodontic materials, which are constantly surrounded by the salivary media. The interactions between saliva and these foreign materials can affect the tribo-corrosion performance.

There are various types of advanced ceramics, metals and polymers that have been employed in modern dentistry, all of which possess many different physical, chemical and aesthetic properties. 316L stainless steel (AISI classification) is one of the longest serving materials in dentistry. The corrosion resistance and mechanical properties of 316L stainless steel make it a desirable option for short- to medium-term use in the human body. The most common dental implementation of $316 \mathrm{~L}$ is in orthodontics where it is used to make wires, brackets and bands for braces [2]. The low cost and low toxicity of $316 \mathrm{~L}$ also make it a favourable choice for longer term implants in developing countries where it is commonly used to make dental crowns.

In recent years, there has been a significant increase in the number of studies examining the tribo-corrosion properties of materials with medical/dental applications. In some recent studies, micro-abrasion and corrosion mechanisms of $316 \mathrm{~L}$ stainless steel in various solutions, including artificial saliva, have been examined. No studies have, however, explicitly focused on the synergistic effects of micro-abrasion and corrosion mechanisms which take place on 316L stainless steel in an artificial saliva solution [2-6].

The purpose of this study is to identify the occurring tribo-corrosion mechanisms where $316 \mathrm{~L}$ stainless steel is exposed to an environment which is similar to the oral cavity. This has been achieved through conducting microabrasion-corrosion tests in an artificial saliva solution. The research results were then analysed and interpreted through tribo-corrosion maps.

\section{Experiment Details}

\subsection{Test Samples}

The dimensions of the $316 \mathrm{~L}$ stainless steel samples were chosen to be $30 \mathrm{~mm}$ in length and breadth, with a thickness of $5 \mathrm{~mm}$ to fit the test apparatus platform. The samples were ground prior to the tests in order to provide a good quality of surface finish. The flatness was confirmed by taking $R_{\mathrm{a}}$ measurements using a Surftest SV-2000 (Mitutoyo, Japan). The density of the samples was confirmed experimentally to be $7.99 \mathrm{e} 6 \mathrm{~g} / \mathrm{cm}^{3}$. The chemical composition (Table 1) of the samples was confirmed using energy dispersive X-ray spectroscopy analysis (EDX).

\subsection{Test Slurry}

The original artificial saliva solution was introduced by Takao Fusayama; however, the composition of the solution has evolved over the years. The composition used for this study is reported in Table 2 [7]. It contained electrolytes that can react with metal alloys in a similar manner to natural saliva and had an approximate $\mathrm{pH}$ of 5.5 [6]. Saliva is a complex organic solution made up of $99 \%$ water; the remaining composition is composed of many inorganic ions (electrolytes), organic compounds (enzymes, antivirals, antibacterials, etc.) and proteins which provide a large range of essential functions. Although saliva has a neutral acidity ( $\mathrm{pH}$ of 7), due to the acidity of the modern western diet, saliva usually becomes acidic during mastication $(\mathrm{pH}$ 5-6). It is not uncommon for proteins, antibacterial agents and enzymes to be added to artificial organic solutions [8]. Yet these components are unlikely to play a major role in the micro-abrasion-corrosion mechanisms of stainless steel during mastication. They have therefore not been included in the solution used in this study.

The artificial saliva solution was mixed with alumina particles (calcined aluminium oxide powder, Logitech, UK) to form the abrasive slurry. This combination simulates the bolus formation during mastication. Alumina particles were chosen due to the hardness of the particles. The hardness of the particles can increase the severity of the tests, and high hardness values have been reported for some foods such as nuts $[9,10]$. Previous works examined the effects of particle size and concentration [11-13]. For these tests, a concentration of $30 \mathrm{gl}^{-1}$ of particles with the average size of $9 \mu \mathrm{m}$ was used to maintain the consistency

Table 1 Chemical composition of 316L stainless steel

\begin{tabular}{ll}
\hline Element & Weight $(\%)$ \\
\hline Carbon, C & $0.03(\max )$ \\
Manganese, Mn & $2.00(\max )$ \\
Phosphorus, P & $0.03(\max )$ \\
Sulphur, S & $0.03(\max )$ \\
Silicone, Si & $0.75(\max )$ \\
Nitrogen, N & $0.1(\max )$ \\
Chromium, Cr & $17-20$ \\
Nickel, Ni & $12-14$ \\
Molybdenum, Mo & $2-4$ \\
Iron, Fe & Bal. \\
\hline
\end{tabular}


Table 2 Chemical composition of artificial saliva [7]

\begin{tabular}{|c|c|}
\hline Compound & Concentration $\left(\mathrm{gl}^{-1}\right)$ \\
\hline $\mathrm{NaCl}$, sodium chloride & 0.4 \\
\hline $\mathrm{KCl}$, potassium chloride & 0.4 \\
\hline $\mathrm{CaCl}_{2} \cdot 2 \mathrm{H}_{2} \mathrm{O}$, calcium chloride dihydrate & 0.795 \\
\hline $\begin{array}{l}\mathrm{NaH}_{2} \mathrm{PO}_{4} \cdot 2 \mathrm{H}_{2} \mathrm{O} \text {, sodium dihydrogen phosphate } \\
\text { dihydrate }\end{array}$ & 0.78 \\
\hline $\mathrm{Na}_{2} \mathrm{~S} \cdot 9 \mathrm{H}_{2} \mathrm{O}$, sodium sulphide nonahydrate & 0.005 \\
\hline $\mathrm{CH}_{4} \mathrm{~N}_{2} \mathrm{O}$, urea & 1 \\
\hline Deionised water & Bal. \\
\hline
\end{tabular}

with the previous studies $[3,6,14]$. The abrasive particles were kept suspended using a mechanical stirrer during the testing, and the solution was replaced after a maximum of $1 \mathrm{~h}$ testing. Table 3 contains the mechanical properties of the test materials.

\subsection{Experiment Apparatus}

For this testing, a TE-66 Micro-Scale Abrasion Tester (Phoenix Tribology, Reading, UK) was used, which operates in accordance with British Standards EN 1071-6: 2007 (Fig. 1). This tester generates round wear scars on the samples using a rotating cratering ball. The test slurry is fed over the contact interface between the sample and the cratering ball using a peristaltic pump connected to an axel that holds the cratering ball in place. This axel is driven by a variable speed DC motor. The test slurry is collected in a solution bath below the contact surface. The load between the sample and the counter-body was applied using a stack of dead weights. Here, the load can be finely adjusted using an adjustable counter-weight.

UHMWPE (ultra-high-molecular-weight-polyethylene) balls (K-mac Plastics, Michigan, USA) with the diameter of $25.4 \mathrm{~mm}$ (1 inch) were used for these tests. UHMWPE possesses a very low friction coefficient and high wear resistance which significantly reduces the interference of the ball in the wear process [15]. UHMWPE is a nonconductive material and therefore has no effects on the corrosion currents. The sliding velocity of the tests was kept constant. Three balls were used during the tests. After each test, the balls were measured for deformation, visually inspected for contamination and cleaned with deionised water. In addition, the balls were incrementally turned in their fixings after each test to prevent any deformation of the spherical shape of the balls. The careful and measured reuse of UHMWPE balls is an economic compromise that has been adopted in other micro-abrasion studies [6, 17].

A potentiostat (ACM Instruments, UK) was used to apply electrical potentials to the samples and measure the corrosion currents. The working electrode (WE) was fixed to the back of the test samples, and the auxiliary (AE) and reference electrodes (RE) were placed in the solution bath. The test samples were insulated using non-conductive tape with a $1 \mathrm{~cm}^{2}$ square section left uncovered. It should be noted that these tests were not conducted in a de-aerated condition.

\subsection{Test Methodology}

These tests were conducted to examine the effects of applied load and applied electrical potential on tribo-corrosion mechanisms of 316L stainless steel. As shown in Table 4, the test matrix consisted of five different applied loads and five electrical potentials. Several recent studies have been conducted to examine the particle size and distribution properties of food bolus of varying hardness $[11,18]$. Chen et al. and Jalabert-Malbos et al. have reported that the forces required to break the food into bolus, ranges from $0.06 \mathrm{~N}$ for egg whites to $24 \mathrm{~N}$ for roasted peanuts with the majority of common foods requiring less than $5 \mathrm{~N}$. Hence, a load range of $0.5-4 \mathrm{~N}$ has been chosen for the tests.

Also, the highest and the lowest reported intraoral potentials in the literature are -431 and $+300 \mathrm{mV}$ [19]. As a result, the selected range of the electrical potentials for these set of experiments was from -600 to $200 \mathrm{mV}$ to reflect the earlier findings and the condition changes from cathodic to anodic [6].

The performance of $316 \mathrm{~L}$ in pure abrasion conditions for each applied load was also investigated. For this purpose, an applied potential of $-960 \mathrm{mV}$ was used to provide a cathodic protection condition for the samples [20]. To study the effects of the presence of the particles in the solution, cyclic sweep tests were also conducted for each load, with and without particles, which produced the polarisation curves. The cyclic sweep polarisation tests lasted $30 \mathrm{~min}$ and applied an electrical potential from -1000 to $500 \mathrm{mV}$ with the sweep rate of $50 \mathrm{mV} \mathrm{s}^{-1}$.

Table 3 Test material mechanical properties $[10,15,16]$

\begin{tabular}{llllll}
\hline Material & Test function & $\begin{array}{l}\text { Density } \\
\left(\mathrm{kg} \mathrm{m}^{-3}\right)\end{array}$ & $\begin{array}{l}\text { Hardness } \\
(\text { Vickers) [GPa] }\end{array}$ & $\begin{array}{l}\text { Young's } \\
\text { modulus }(\mathrm{GPa})\end{array}$ & $\begin{array}{l}\text { Fracture toughness } \\
\left(\mathrm{MPa} \mathrm{m}^{-1 / 2}\right)\end{array}$ \\
\hline AISI 316L SS & Test sample & 7990 & $(195)[1.912]$ & 192 & 100 \\
Alumina & Abrasive particles & 3800 & $(2035)[1.912]$ & 351 & $3.5-6$ \\
UHMWPE & Cratering ball (counter surface) & $931-935$ & $(541)[5.306]$ & 0.689 & 3.5 \\
\hline
\end{tabular}




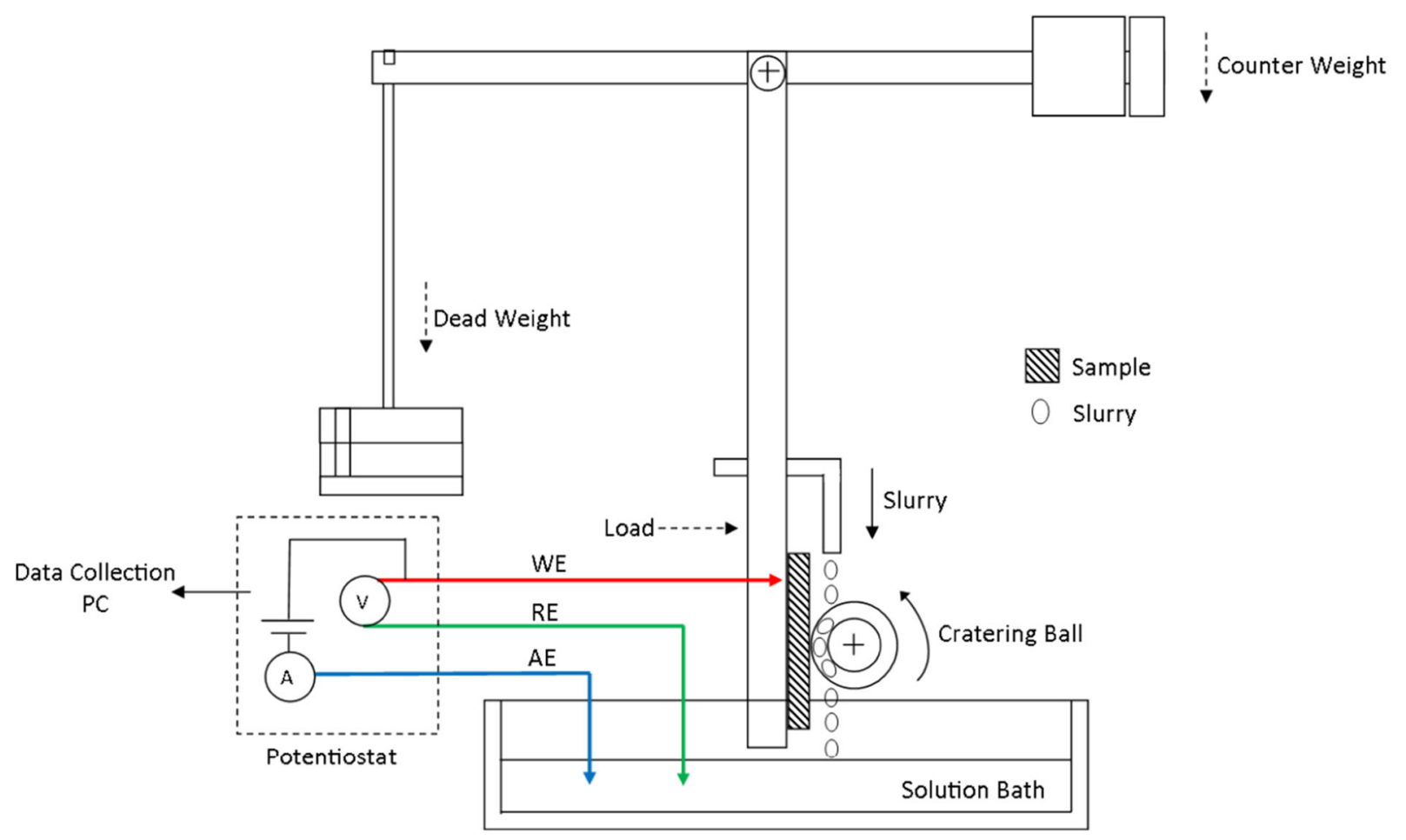

Fig. 1 TE-66 micro-scale abrasion tester

Table 4 Test conditions

\begin{tabular}{ll}
\hline Applied loads $(\mathrm{N})$ & $0.5,1,2,3,4$ \\
Applied electrical potentials (pure & $(-960),-600,-400,-200$, \\
$\quad$ abrasion tests) (mV) & 0,200 \\
Sliding speed (rpm) & 150 \\
Sliding distance (m) & $\approx 359$ \\
Test duration (mins) & 30 \\
Cyclic sweeps & $0.5,1,2,3,4 \mathrm{~N}$ (with and \\
& without particles)
\end{tabular}

The cratering ball was rotating at the speed of $150 \mathrm{rpm}$ for the duration of $30 \mathrm{~min}$. The combination of the rotational speed and test length resulted in a total sliding distance of $359 \mathrm{~m}$ per test. Previous studies have shown that the average sliding distance per tooth each day is approximately $1 \mathrm{~m}$. Thus, each test approximates 1 year of material use as a crown [14].

The test outcomes were cross-referenced with the previous studies. Therefore, only the tests with abnormal outcomes were repeated in order to confirm the reproducibility. The abnormal results due to the probable occurrence of errors are not reported or used to create averages and scatterings. To avoid errors in the calculations, all were done in excel without rounding.

\section{Results}

\subsection{Polarisation Curves}

Figures $2 \mathrm{a}, \mathrm{b}$ are the polarisation curves generated from the cyclic sweep tests for all applied loads, both without and with particles. Figure 2a displays more uniformity in corrosion current densities for all loads in the absence of abrasive particles. This is in comparison with Fig. $2 b$ where the abrasive particles are present. It can be seen that the corrosion current densities for the tests with particles are higher than the tests without particles. With the exception of $0.5 \mathrm{~N}$ during cathodic conditions, all the corrosion currents densities are almost ten times greater with particles than without particles.

\subsection{Alumina Particles}

In order to have a better understanding of the function of the alumina particles in the tests, a small amount of the fresh particles was compared with the used particles collected from the solution bath. The images were taken using a S3700 (Hitachi, Japan) Tungsten Filament Scanning Electron Microscope (SEM). As shown in Fig. 3, the size 
of the particles did not seem to be altered after the test. This confirmed the validity of the particles material selection to avoid degradation. If the hardness of the abrasive particles and the target surface are relatively close, the wear rate can vary due to the occurrence of a phenomenon known as 'soft abrasion'. This takes place when the hardness of the abrasive particles alters during the interaction [21]. It should be noted that the size values in the two images are there to facilitate the comparison.

The cratering ball was also inspected, after a test and before cleaning, for the occurrence of particle embedment on the ball surface. As depicted in Fig. 4, the embedment was observed on the surface and this was confirmed using EDX analysis. The embedment of particles on the cratering surface increases the tendency of transition of the abrasion mechanism from 3-body rolling towards 2-body grooving [22].

\subsection{Wear Scars}

Scanning Electron Microscopy (SEM) was used to measure the wear scar diameters and take micrographs to identify the wear mechanisms which created the scars. As expected

(a)
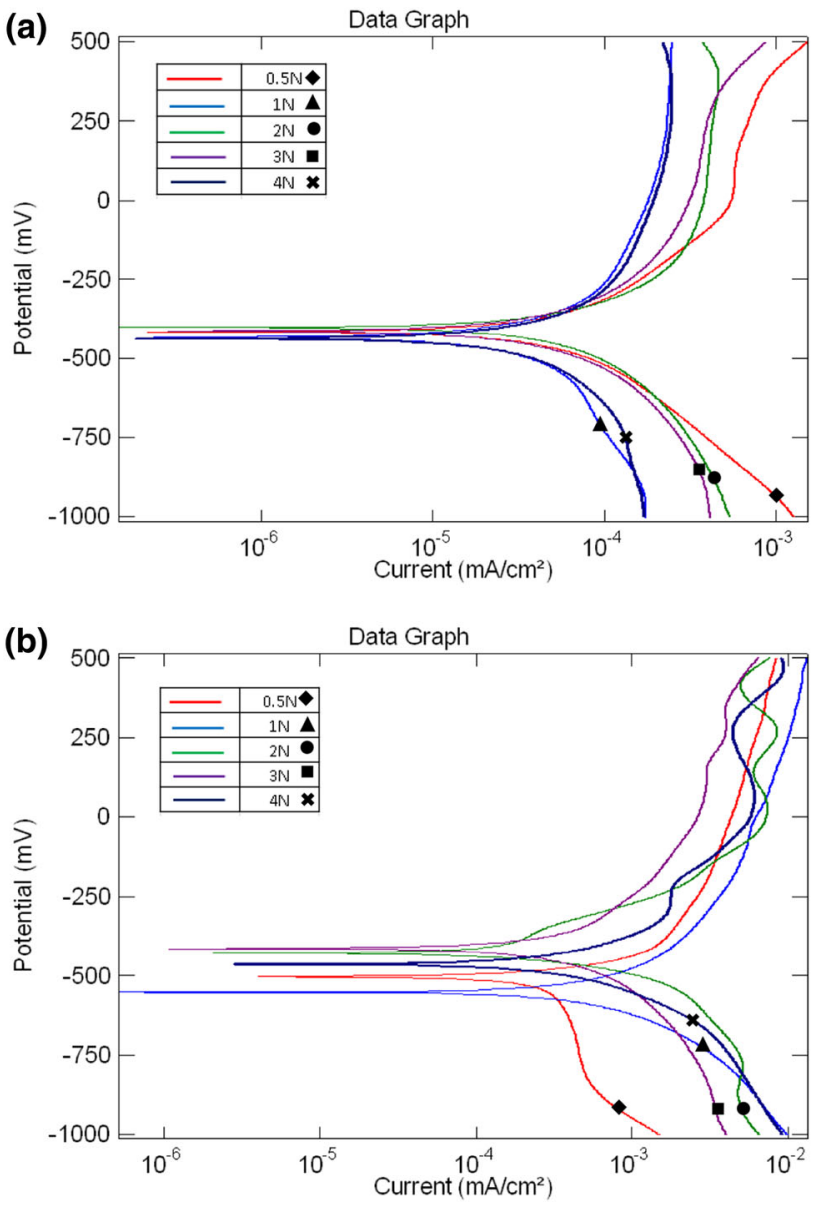

Fig. 2 a Polarisation tests without particles. b Polarisation tests with particles and demonstrated in Fig. 5, the dominant wear mechanism was 2-body grooving in all cases. The only difference between the scars was the severity which resulted in the variation of the material loss. Figure 5 represents an example of this similarity. It was also noted that none of the SEM micrographs appeared to show any visual signs of surface corrosion. Although this was consistent with the previous studies findings $[3,6]$, after completing the SEM, a number of samples were cut through the scars and mounted to investigate the cross-section of the scars. This provided an opportunity for the inspection of the crosssectional shape of the scars, existence of corroded layers on the scars. Figure 6 exhibits the images that were taken from the scars cross-sections using an optical microscope (Olympus GX51, Japan). Figure 6a confirms the hemispherical shape of the scars. By increasing the magnification and focusing in the middle area of the scars, it was still not possible to identify any clear corrosion layers. This can be due to the lower mass of corrosion wear recorded comparing to the mechanical wear. This is discussed in detail in the next section. From the microscopy results, it was also noted that the substrate material did not exhibit any form of uninform corrosion or pitting. Figure $6 \mathrm{c}$ shows the difference between the sample surface and the scar surface and Fig. 6d is a cross-section of the grooves on a scar surface.

\subsection{Weight Loss}

The wear scars created during testing were analysed using the method developed by Yue and Shi [20]. For each test, the total weight loss $\left(K_{\mathrm{ac}}\right)$ was divided into weight loss due to micro-abrasion $\left(K_{\mathrm{a}}\right)$ and to corrosion $\left(K_{\mathrm{c}}\right)$.

$K_{\mathrm{ac}}=K_{\mathrm{a}}+K_{\mathrm{c}}$

The total weight loss $\left(K_{\mathrm{ac}}\right)$ was calculated by multiplying the density of the sample material and the volume loss $(V)$ which can be calculated using Eq. (2) as the hemispherical shape of the scars was confirmed in the previous section [23]:

$V=\frac{\pi b^{4}}{64 R}($ when $b<<R)$

where $V$ is the volume loss; $b$ is the diameter of wear scar $(\mathrm{m}) ; R$ is the cratering ball radius $(\mathrm{m})$

The corrosion weight loss $\left(K_{\mathrm{c}}\right)$ was calculated using a variation of Faraday's Law:

$K_{\mathrm{c}}=\frac{M I_{\text {corr }} t}{Z F}$

where $K_{\mathrm{c}}$ is the corrosion weight loss $(\mathrm{g}) ; M$ is the atomic mass; $I_{\text {corr }}$ is the corrosion current density $\left[\mathrm{mA} \mathrm{cm}^{-2}\right]$; $t$ is the experiment duration ( $\mathrm{sec}) ; Z$ is the number of valence electrons; $F$ is the Faraday's constant, 96,500 $\left(\mathrm{C} \mathrm{mol}^{-1}\right)$ 

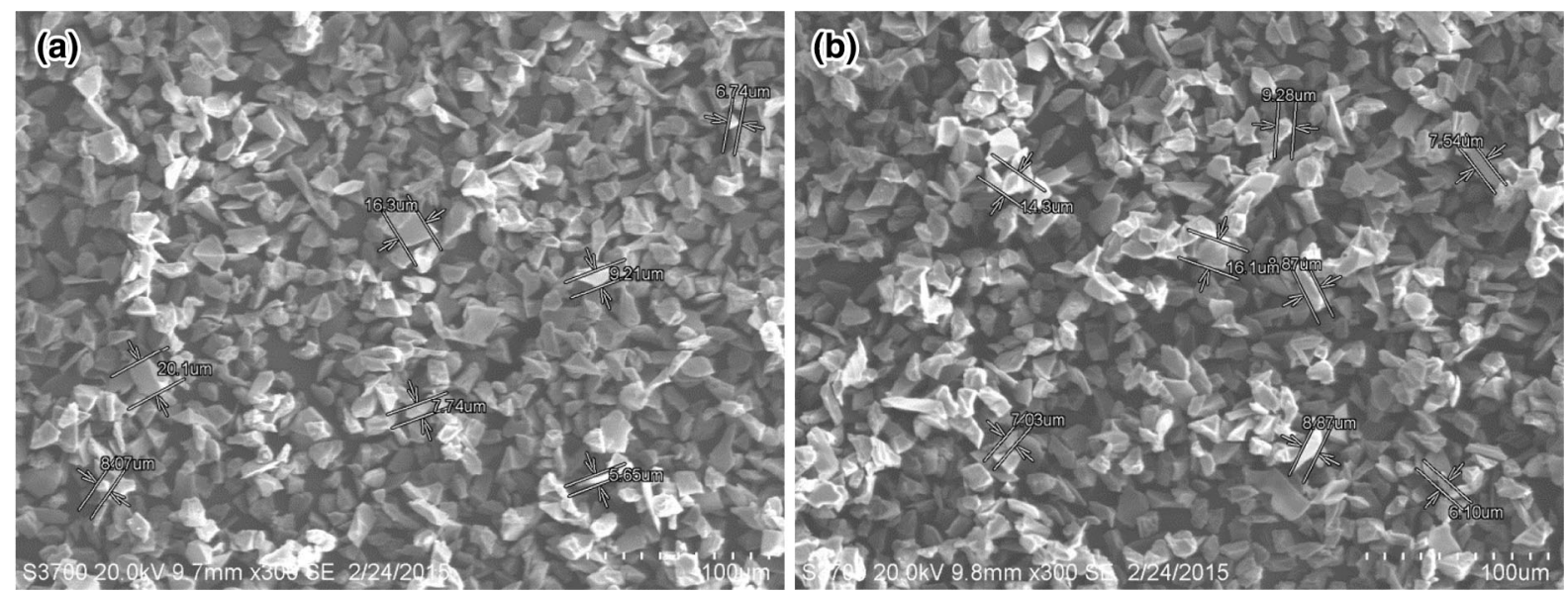

Fig. 3 Particle distribution $\mathbf{a}$ before and $\mathbf{b}$ after testing
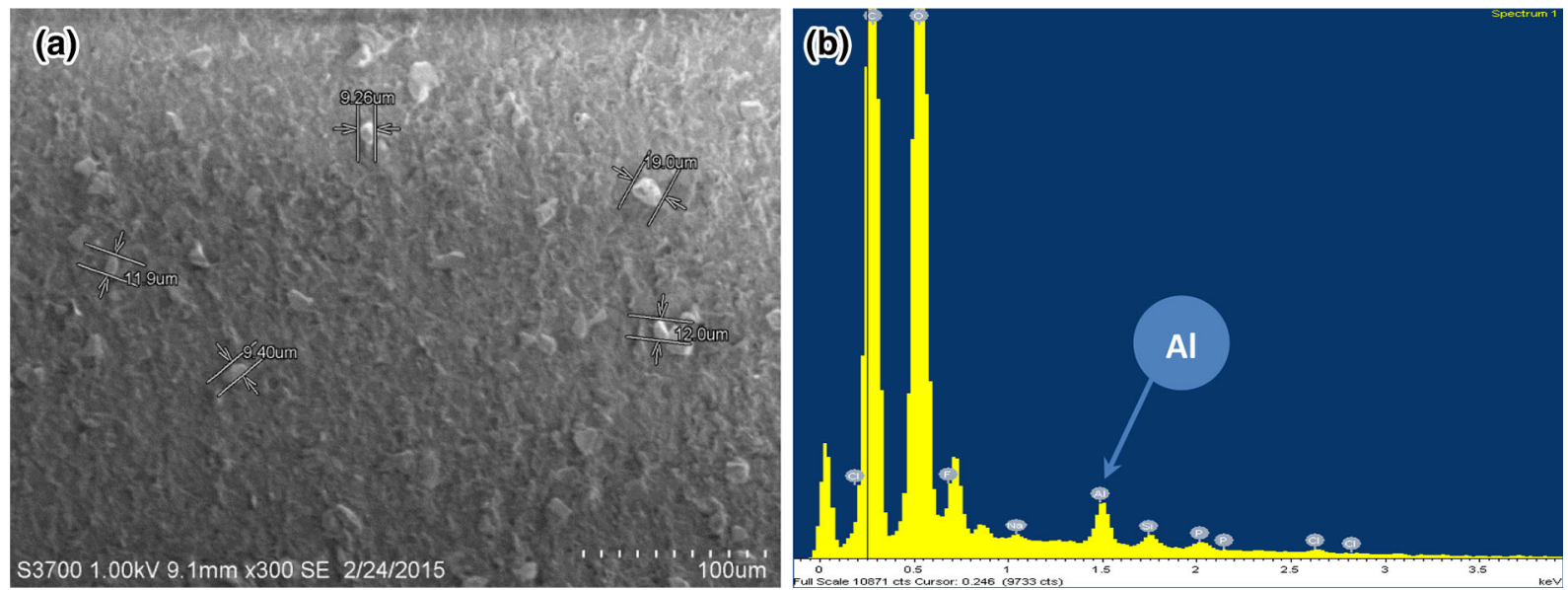

Fig. 4 Particle embedment on the cratering ball surface after testing a SEM image, b EDX analysis

Micro-abrasion weight loss $\left(K_{\mathrm{a}}\right)$ can also be divided up into pure micro-abrasion weight loss $\left(K_{\mathrm{ao}}\right)$ and the synergistic effect of corrosion on the micro-abrasion $\left(\Delta K_{\mathrm{a}}\right)$ :

$K_{\mathrm{a}}=K_{\mathrm{ao}}+\Delta K_{\mathrm{a}}$

The pure micro-abrasion weight loss $\left(K_{\mathrm{ao}}\right)$ was calculated using Eq. (2), the material density and the wear scars from the pure micro-abrasion tests (cathodic conditions at $-960 \mathrm{mV}$ ) for each applied load.

Similarly, corrosion weight loss $\left(K_{\mathrm{c}}\right)$ can be divided up into pure corrosion weigh loss $\left(K_{\mathrm{co}}\right)$ and the additive effect of micro-abrasion on the corrosive weight loss $\left(\Delta K_{\mathrm{c}}\right)$ :

$K_{\mathrm{c}}=K_{\mathrm{co}}+\Delta K_{\mathrm{c}}$

Approximate values of pure corrosion weight loss $\left(K_{\mathrm{co}}\right)$ were calculated using Eq. (3) and the ' $I_{\text {corr }}$ ' values from the polarisation curves without particles $\left(I_{\text {corro }}\right)$ for every applied load and each electrical potential.

Figure 7 presents the calculated total weight loss $\left(K_{\mathrm{ac}}\right)$, the micro-abrasion weight loss $\left(K_{\mathrm{a}}\right)$ (LHS axes) and the corrosion weight loss $\left(K_{\mathrm{c}}\right)$ (RHS axis) results. It should be noted that the scales of the LHS axes are much higher than the RHS ones. The results show that for every test condition, the total and micro-abrasion weight loss values are very close in magnitude, whilst the corrosion weight loss is much less. There is also very little variation in total/microabrasion weight loss for each load over a range of applied potentials. For each applied load, the corrosion weight loss increases with increasing applied potential. There is only a very small increase in abrasion weight loss when corrosion is included $\left(K_{\mathrm{ao}} \gg \Delta K_{\mathrm{a}}\right)$. Yet the corrosion is roughly ten times greater when abrasion is included $\left(K_{\mathrm{c}} \approx 10 K_{\mathrm{co}}\right)$. 

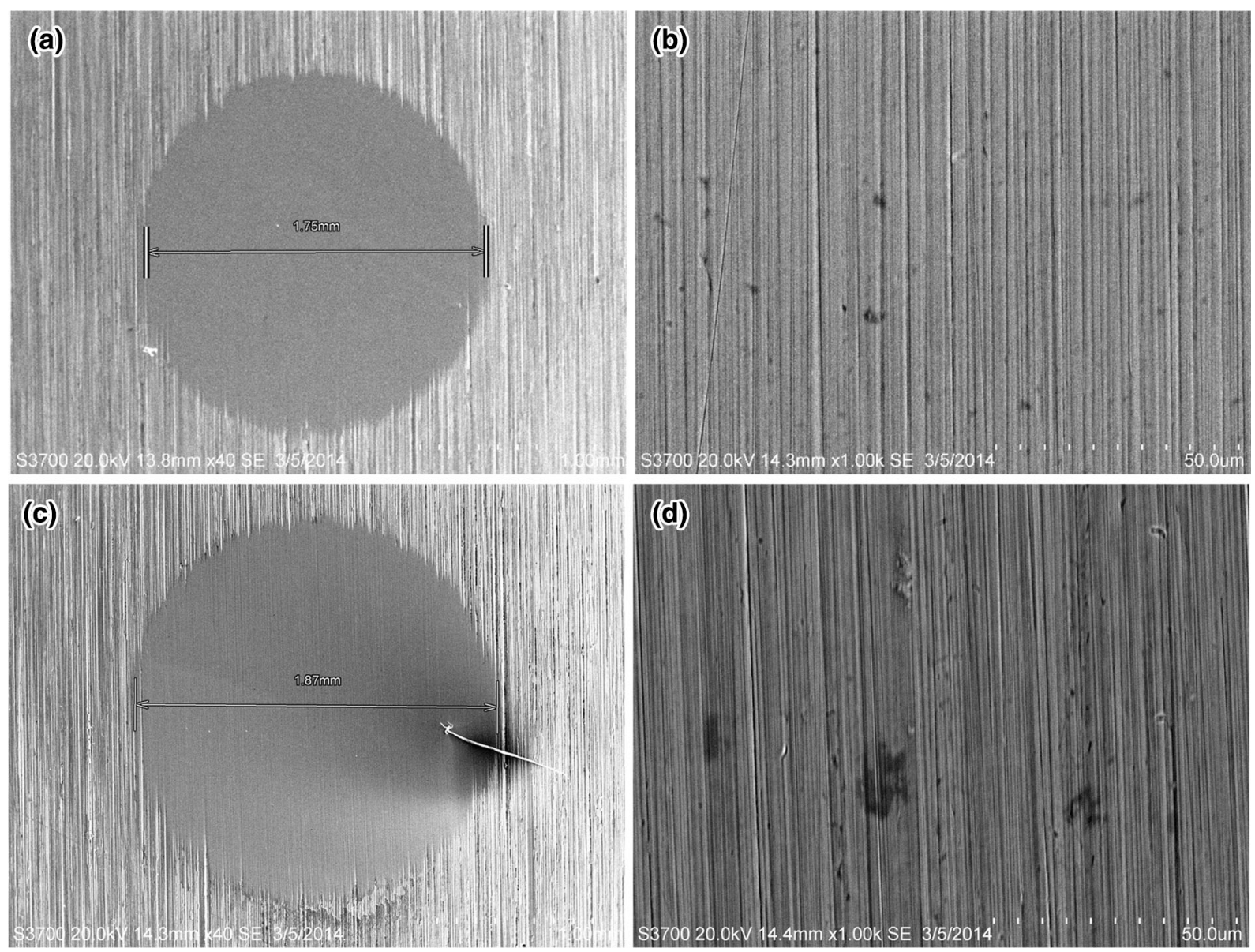

Fig. 5 SEM micrographs of the wear scar from the cyclic sweep tests with particles at a $0.5 \mathrm{~N}$ wear scar diameter $\times 40$, b $0.5 \mathrm{~N}$ magnified scar $\times 1000$, c $2 \mathrm{~N}$ wear scar diameter $\times 40$ and $\mathbf{d} 2 \mathrm{~N}$ magnified scar $\times 1000$

\section{Discussion}

The ability to predict wear of materials is a universal challenge crucial to successful application of new materials into different technologies. There are numerous methods to describe wear data such as tabulated wear rates or elucidation of the dominant wear mechanisms using micrographs [24]. Of all these methods, a more comprehensive method is to link the wear rates and wear mechanisms in a much wider range of sliding conditions known as 'wear maps'. There are a limited number of standardised wear testing methods, and often the variables of a study are incomparable with one another. Hence, wear (mechanism) maps can be an extra-ordinary informative tool to link mechanisms to operating parameters [25].

\subsection{Tribo-corrosion Maps}

Wastage and mechanism maps were generated for $316 \mathrm{~L}$ stainless steel using the test results (with particles), and mapping techniques have been developed in previous studies [26, 27]. The maps were drawn by plotting the results of the 25 tests on a chart and interpolating between the points to determine the boundary lines. It had to be assumed that the wear results varied linearly between each condition.

For the wastage map (Fig. 8), the categories of wear were taken from previous studies $[3,6,14,20]$ and adapted as follows:

The wastage map clearly shows that applied electrical potential had no significant effect on the total wear compared to the applied load. This is due to the fact that the amount of material loss caused by corrosion was much lower than micro-abrasion. As a result, any variation in material loss due to corrosion has no significant effect on total wear. The map shows that the highest wastage occurred at $2 \mathrm{~N}$ and the lowest wastage occurred at loads lower than $1 \mathrm{~N}$.

It was noted that the highest load did not cause the highest material loss. This may be due to entrainment issues associated with abrasive particles at higher loads. Higher loads produce higher pressure in the contact area, 

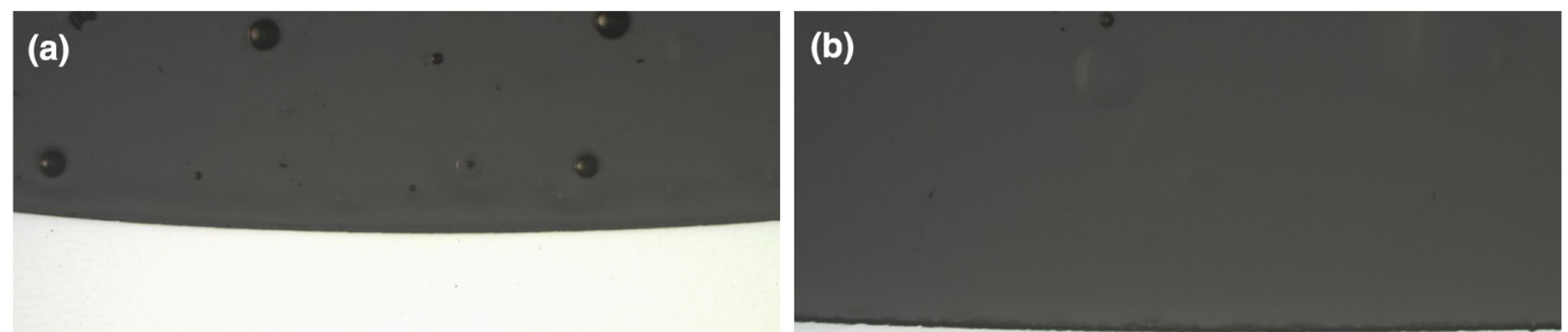

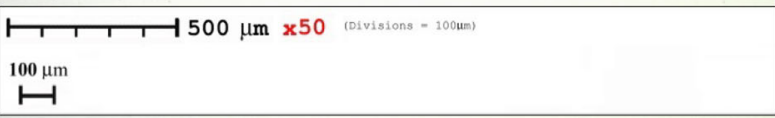
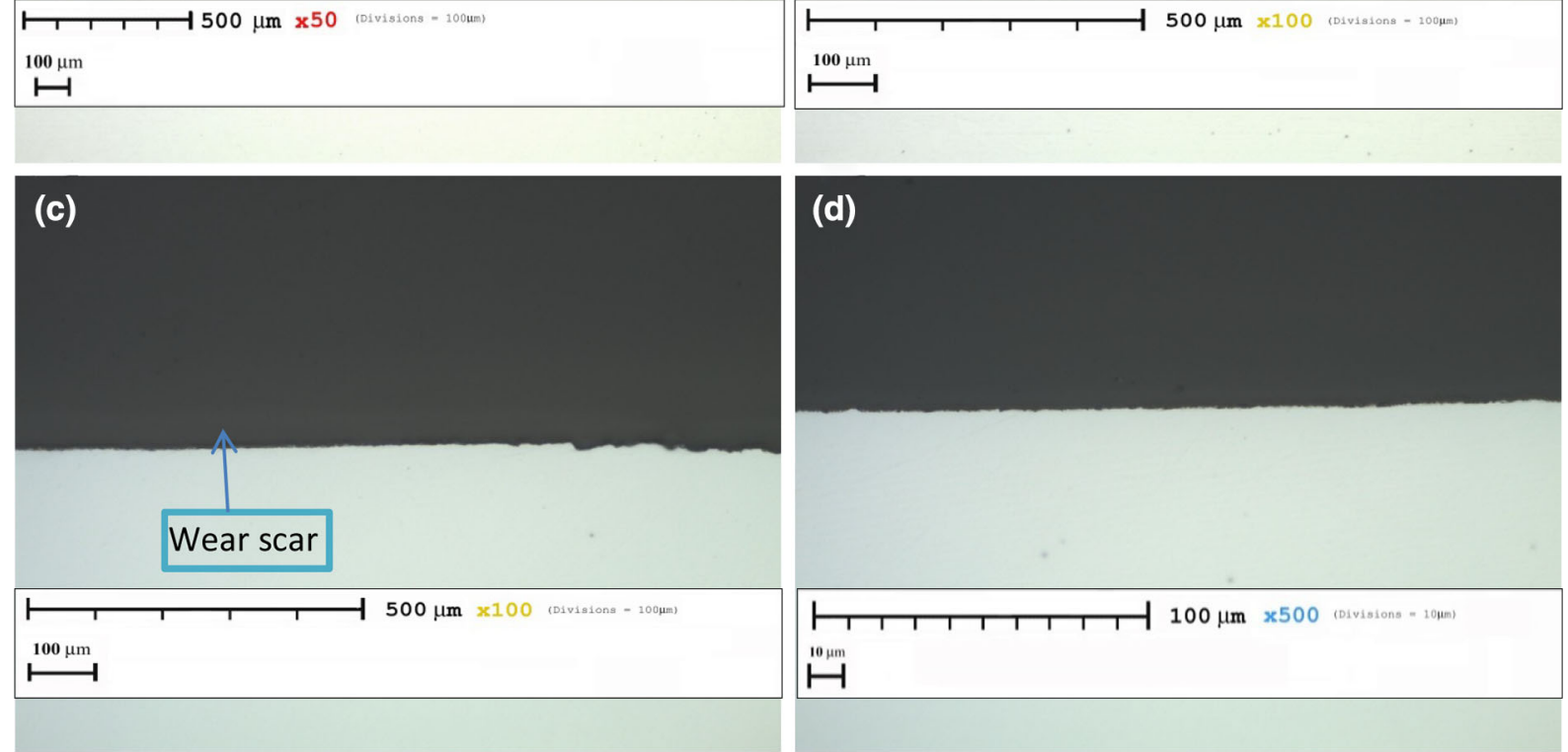

Fig. 6 Optical microscopy images from the scars cross-sections a $0.5 \mathrm{~N}-600 \mathrm{mV}$-full scar, b $2 \mathrm{~N}$ cyclic sweep test with particles-full scar, c $2 \mathrm{~N}-400 \mathrm{mV}$-scar edge and d $0.5 \mathrm{~N}-600 \mathrm{mV}$ middle area

which may reduce the frequency of particle entrainment. This may result in unexpected wear rates. Thus, regardless of the type of the surface material and despite the presence of load and abrasive particles, the wear rate may decrease due to entrainment of particles for a period of time. Also, Lansdown and Price [28] and Stack and Mathew [22] have proposed that at higher loads, transitions between the wear mechanisms are not unexpected. This suggests that the relation between the material loss and applied load is more complicated than a linear relationship between the applied load and wear rate. Another possible reason for this pattern of behaviour is the duration of the tests. Ridges are generally formed at the early stages of development of the scar and typically do not alter the background profile of the wear crater [29]. Despite of the presence of load and abrasive particles, the wear rate may decrease due to entrainment of particles in the formed ridges. However, when the ridge is eventually removed, a sudden increase is observed in the wear rate. Previous work by the current authors [6] for a similar load range showed the highest wear rate was found to be at $4 \mathrm{~N}$ load, but this was after $3 \mathrm{~h}$ of testing.

For the mechanism map (Fig. 9), the categories of the mechanisms were adopted from the previous work of the group [20]. An additional 'pure micro-abrasion' category was added since the map was micro-abrasion dominated. The categories were as follows:

The mechanism map of 316L SS stainless steel shows that the wear mechanism is heavily micro-abrasion dominated. For example, from the results which showed that at the highest ratio of corrosion to micro-abrasion $(0.5 \mathrm{~N}$ at $200 \mathrm{mV})$, micro-abrasion is still thirty times greater than the corrosion. The mechanism map also highlights that under pure micro-abrasion (cathodic); the highest electrical potential was observed for $2 \mathrm{~N}$ load and at the lowest for 0.5 and $1 \mathrm{~N}$. The Pourbaix Diagrams for iron and chromium [30] indicated that the corrosion of iron begins at a higher electrical potential than chromium. This suggests that more of the chromium oxide passive film has been removed for loads of $2 \mathrm{~N}$ compared to 0.5 and $1 \mathrm{~N}$. 


\section{(a)}

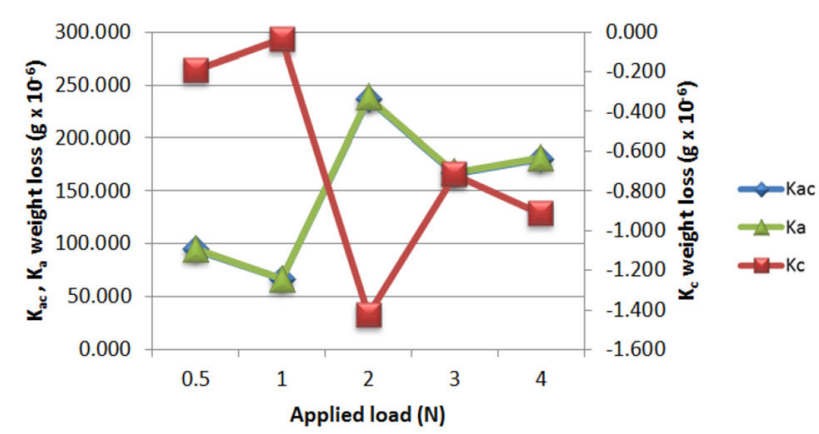

(c)

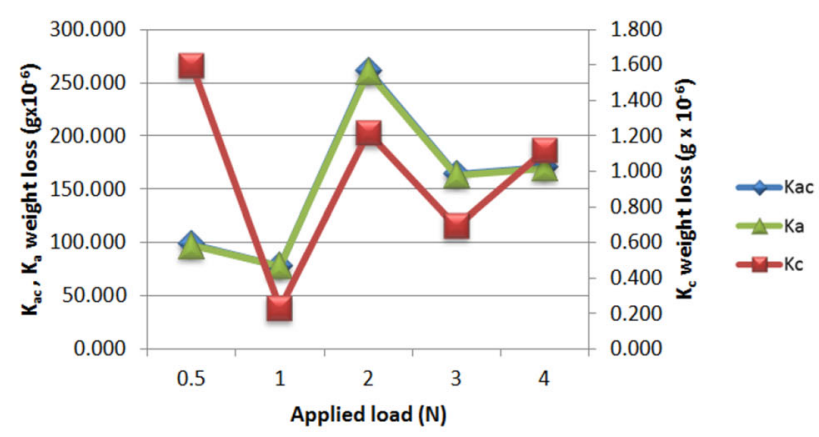

(b)

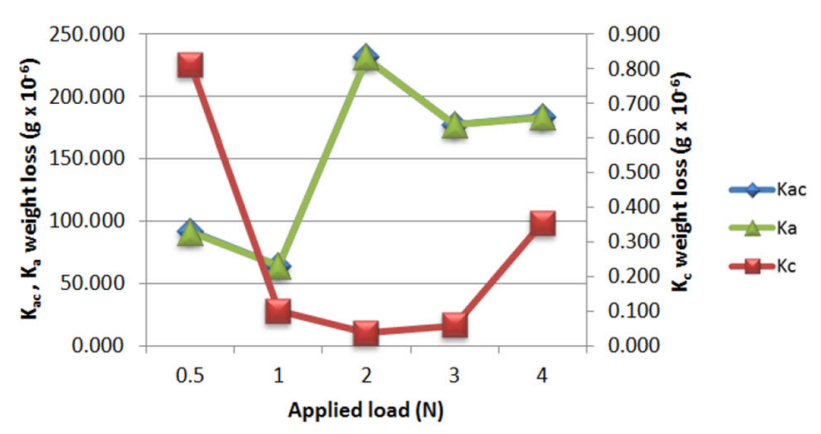

(d)

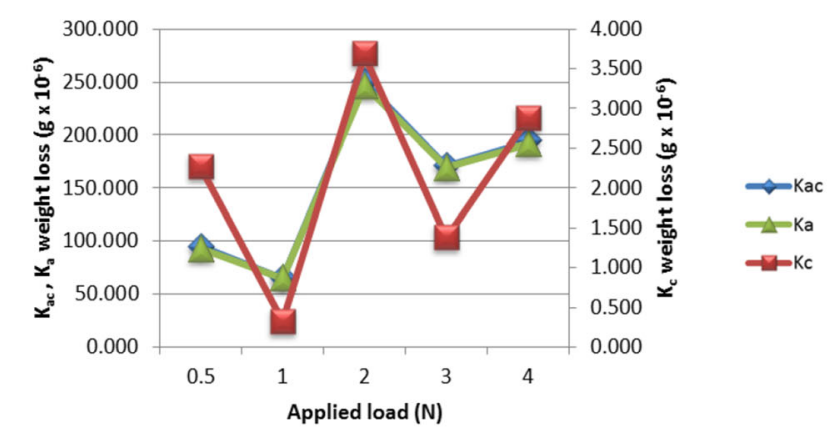

(e)

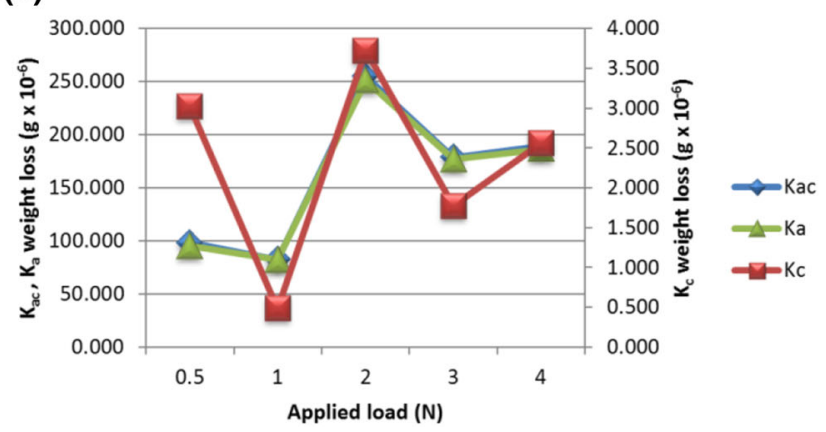

Fig. 7 Weight loss graphs of $316 \mathrm{~L}$ stainless steel for the load range of $0.5-4 \mathrm{~N}$ at a $-600 \mathrm{mV}, \mathbf{b}-400 \mathrm{mV}$, c $-200 \mathrm{mV}$, d $0 \mathrm{mV}$, and e $+200 \mathrm{mV}$

This is consistent with the results displayed in the wastage map that displays the highest wastage at $2 \mathrm{~N}$ and the lowest wastage at load below $1 \mathrm{~N}$.

\subsection{Corrosion and Passive Film Removal}

For all applied loads, the corrosion current densities were greater for the cyclic sweeps (polarisation curves) with the presence of abrasive particles than that in their absence (Fig. 2). This is an indication that the chromium oxide passive film, which protects the iron from oxidising, had been removed by the abrasion of the alumina particles. This could mean that the corrosion in tests without particles is largely from the chromium reacting with the chloride in the saliva solution, whilst the corrosion in tests with particles is mostly from iron oxidation on the samples' unprotected surface [31].

This can be confirmed by the electrical potential at which passivation occurs and by the presence of repassivation phenomenon observed in the polarisation curves for 2, 3 and $4 \mathrm{~N}$ with particles (Fig. 2b). According to the Pourbaix diagram for chromium [30], pure chromium will not passivate in a chloride solution with a $\mathrm{pH}$ of 5.5 , but in other solutions, chromium will passivate at potentials above $-500 \mathrm{mV}$. Since the artificial saliva solution contains a low chloride concentration and non-chloride 
Fig. 8 Wastage map of $316 \mathrm{~L}$ stainless steel in artificial saliva

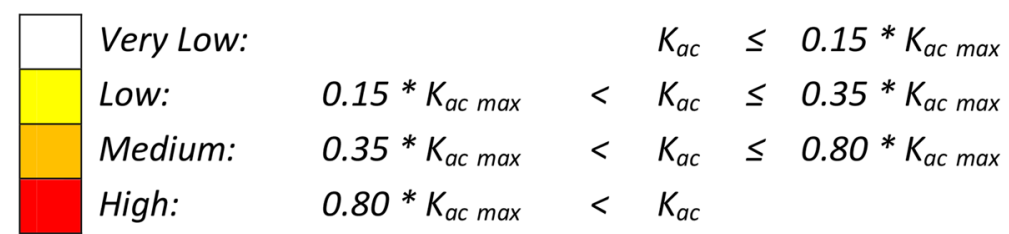

\section{Wastage Map of 316L SS}

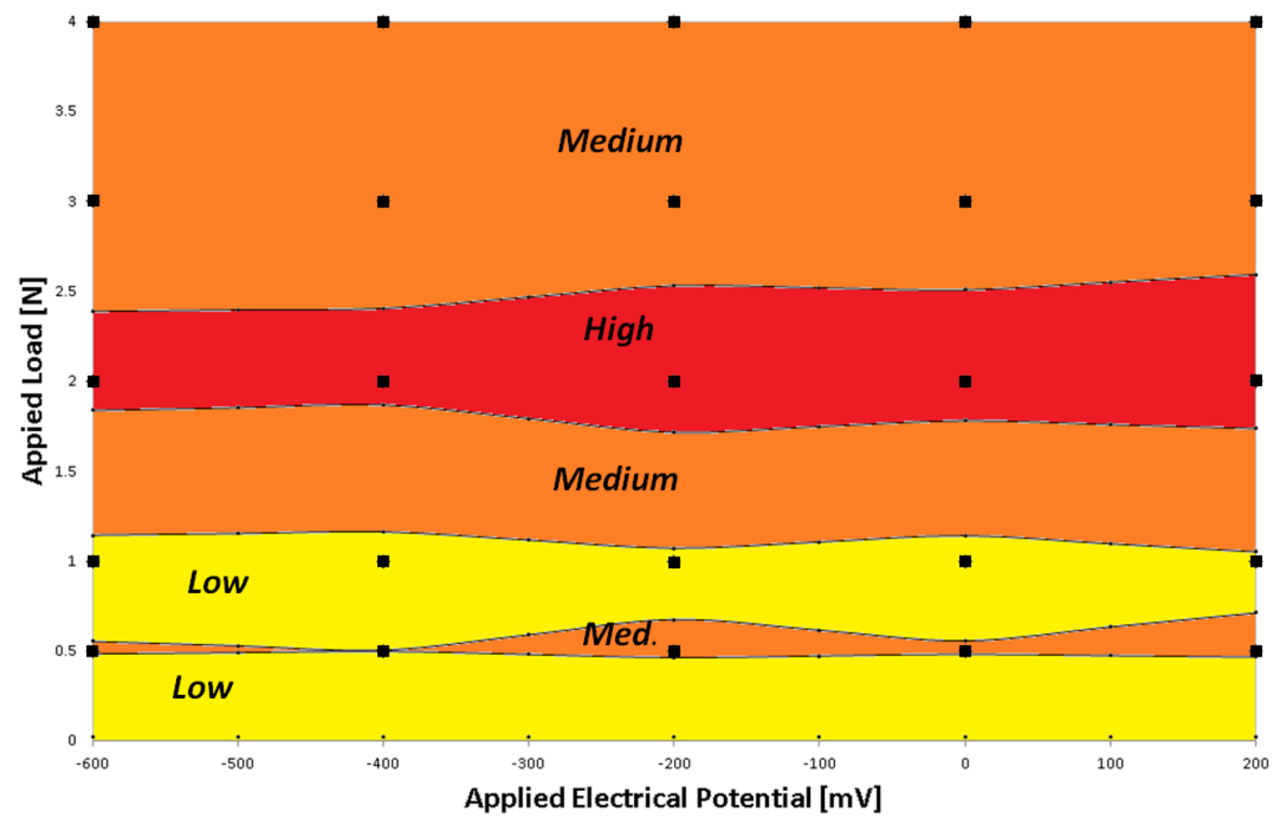

electrolytes, it can be assumed that the passivation at approximately $-500 \mathrm{mV}$ in all polarisation curves (Figs. 2a, b) is a result of the corrosion of the chromium oxide passive film. For iron, the Pourbaix diagram for iron indicates passivation in a solution of $\mathrm{pH}$ of 5.5 at applied electrical potentials greater than $300 \mathrm{mV}$. This is a likely explanation for the repassivation phenomena observed in the polarisation curves for 2, 3 and $4 \mathrm{~N}$ with particles.

The weight loss results (Fig. 3) indicate a relationship between the rate of micro-abrasion and corrosion. For applied electrical potentials greater than $-200 \mathrm{mV}$ (anodic), the rate of corrosion increases when the rate of microabrasion increases; conversely, the rate of corrosion decreases when the rate of micro-abrasion decreases (Fig. 10). This would appear to suggest, that for anodic conditions, when the rate of micro-abrasion increases, the rate at which the chromium oxide passive film is removed also increases resulting in more iron oxidation. If this is correct then there should also be a relationship between the rate of micro-abrasion and presence of repassivation phenomena. Repassivation phenomena can be observed in the polarisation curves of 2,3 and $4 \mathrm{~N}$ which are the three loads with the highest micro-abrasion. The loads resulting in the lowest micro-abrasion, 0.5 and $1 \mathrm{~N}$, display no repassivation. $2 \mathrm{~N}$ is the load with the highest microabrasion and it has a greater frequency of repassivation. Of the loads displaying repassivation, $3 \mathrm{~N}$ has the lowest micro-abrasion and this also has the lowest frequency of repassivation. This suggests that higher rates of microabrasion also remove the repassivation film at a higher rate.

\subsection{Total Wear}

The non-linear relationship between applied load and micro-abrasion observed in this study's results is consistent with a previous study of $316 \mathrm{~L}$ stainless steel in artificial saliva [6]. Other recent studies of different materials and solutions suggest that applied electrical potential has no observable effect on the rate of micro-abrasion [20]. This conclusion appears to be consistent with the results of this study since the total wear of each applied load is constant for all applied electrical potentials. This can be further confirmed by the graph above (Fig. 11) which displays the mean total micro-abrasion mass change for each applied load with a standard error showing the wear variation over all applied electrical potentials. The 'error' shows a very 
Fig. 9 Mechanism map of 316L stainless steel in artificial saliva
Pure micro-abrasion:

Micro-abrasion:

Micro-abrasion-corrosion:

Corrosion-micro-abrasion:

Corrosion:

$\begin{aligned} & K_{d} / K_{a} \leq 0 \\ & 0<K_{d} / K_{a}<0.1 \\ & 0.1 \leq K_{d} / K_{a}<1 \\ & 1 \leq K_{d} / K_{a}<10 \\ & 10 \leq K_{d} / K_{a}\end{aligned}$

Mechanism Map of 316L SS

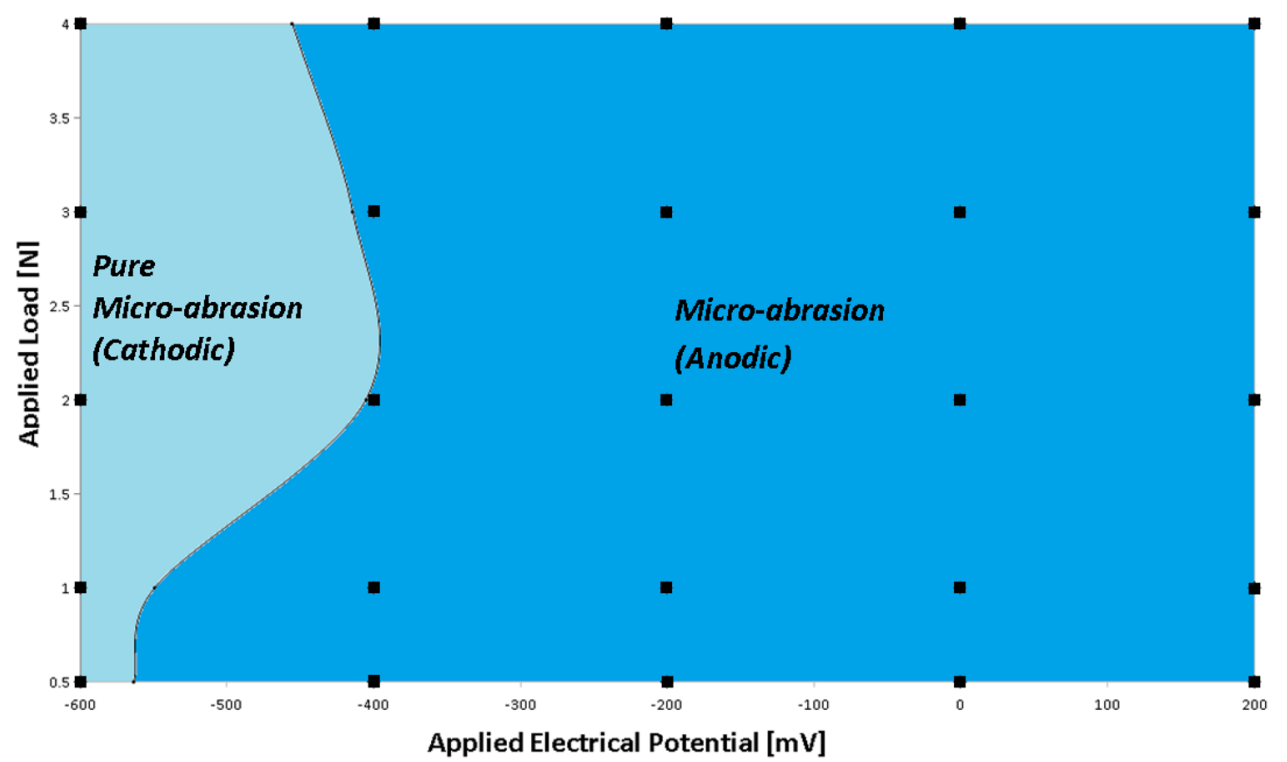

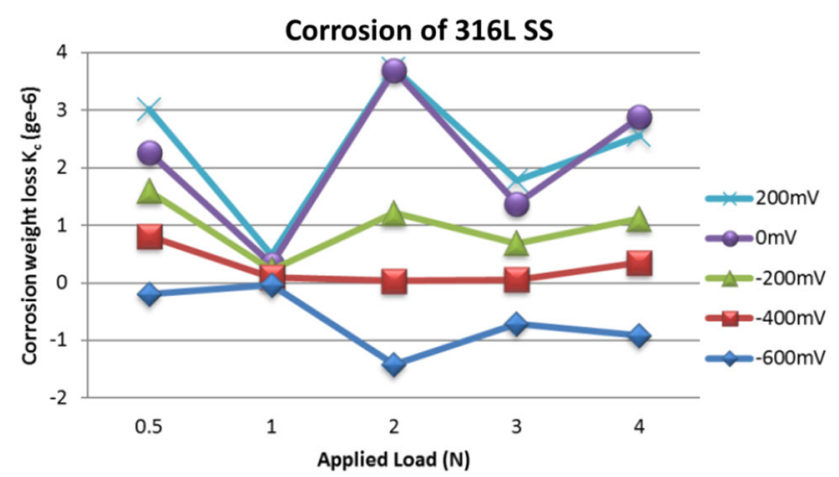

Fig. 10 Graph of corrosion of 316L stainless steel

low variation between the 5 applied electrical potentials. A standard error for every electrical potential cannot be generated because only abnormal (unreportable) test results were repeated.

\subsection{Wear Severity Coefficients}

In recent literature, two different methods have been used to express the severity of total wear. The first is based on the work of J. F. Archard who established an equation to predict the volume loss of a material [32]:

$V=\frac{K W L}{H}$

where ' $V$ ' is the predicted volume loss, ' $K$ ' is a constant dimensionless coefficient of wear, ' $W$ ' is the applied load, ' $L$ ' is the total sliding distance and ' $H$ ' is the hardness of the softer of the two surfaces (in Vickers). If the measured volume loss is used for ' $V$ ', then ' $K$ ' can be calculated for each test condition. Archard's prediction assumes that total wear will increase linearly as load and sliding distance increase. This is has been proven true for adhesive sliding wear and to some extent for hard particle abrasive wear $[33,34]$. For non-linear wear, ' $K$ ' can then be classed as a measure of severity (Fig. 12).

The results for Archard's wear coefficients show that the coefficients are constant for all applied electrical potentials for each applied load. The results also show a decreasing severity with increasing applied load with the highest severity occurring at $0.5 \mathrm{~N}$ and the lowest at $4 \mathrm{~N}$. This is likely due to the fact that Archard's prediction assumes that the greatest wear will be observed at higher loads. 


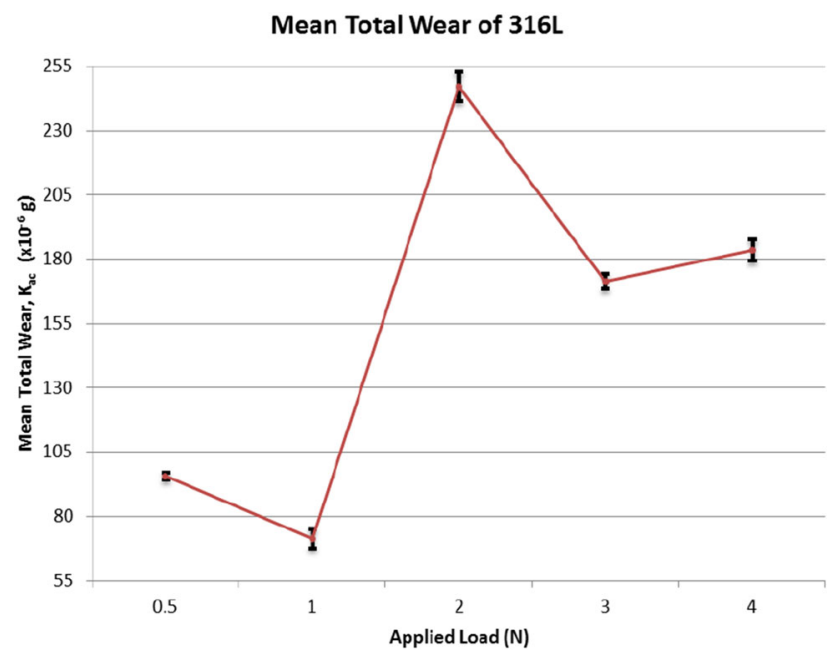

Fig. 11 Mean total wear for all loads with standard error for all applied electrical potentials

The second method for expressing wear severity was established by Adachi and Hutchings [26] and is expressed as

$S=\frac{W}{A v H^{\prime}}$

$\frac{1}{H^{\prime}}=\frac{1}{H_{\mathrm{s}}}+\frac{1}{H_{\mathrm{b}}}$

$A=\pi\left(a^{2}+2 R D\right)$

where ' $S$ ' is a dimensionless coefficient of wear severity, ' $W$ ' is applied load, ' $A$ ' is the wear scar surface area, ' $v$ ' is the volume fraction of abrasive particles in the solution, ' $H$ ' is the combined hardness of the sample $\left(\mathrm{H}_{\mathrm{s}}\right)$ and the cratering ball $\left(H_{\mathrm{b}}\right)$ in $P a$, ' $a$ ' is the radius of the Hertzian contact area, ' $R$ ' is the cratering ball radius and ' $D$ ' is the particle diameter. The volume fraction of abrasive particles in the solution ' $v$ ' is 0.03 . Using the Hertzian formulae for a ball/flat surface, the contact pressure between the cratering ball and the sample surface varies from 0.35 to

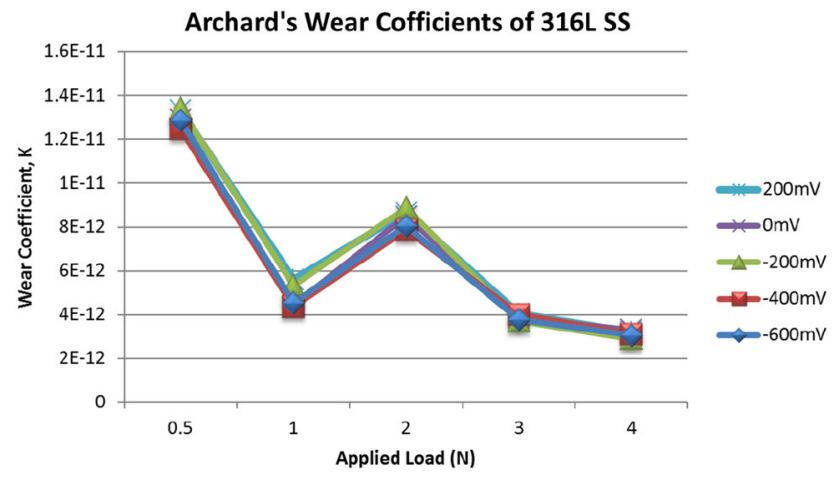

Fig. 12 Archard's coefficient of wear for 316L stainless steel
2.1 MPa. The contact pressure between the abrasive particles and the sample surface will be much higher. For this study, the scar surface area was calculated using the scar diameter. This method of expressing the wear severity produces an increasing linear relationship between severity ' $S$ ' and applied load (Fig. 13).

There does not seem to be any clear correlation between wear severity ' $S$ ' (Fig. 11) and corrosion rate, but it does produce an increasing linear relationship with applied load. There does also appear to be a corresponding relationship between total (micro-abrasive) wear (Fig. 11) and corrosion (Fig. 10) during anodic conditions. An increase in total wear between load conditions is accompanied by an increase in corrosion rate, and conversely, a decrease in total wear is accompanied by a decrease in corrosion rate. Also, by comparing the two methods of evaluating the wear rate (Figs. 12,13), an existing correlation can be suggested between the Archard wear coefficient and inverse of wear severity:

$K \propto \frac{1}{S}$

\subsection{Wear Regimes}

As mentioned earlier, the non-linear relationship between applied load and micro-abrasion is largely due to the transitions between different wear regimes. The two simplified classifications of hard particle abrasive wear regimes are two- and three-body abrasive wear [21]. More recent studies in abrasion wear regime transitions have established that there are more regimes including mixtures of these wear regimes but the fundamental concepts and classifications of these two modes still hold [17, 22]. It was originally thought that three-body rolling wear occurs at lower loads and this transitions to two-body grooving at higher loads [21]. More recent studies have established that as applied load is increased, the wear regime transitions from a mixture of three- and two-body wear to two-body

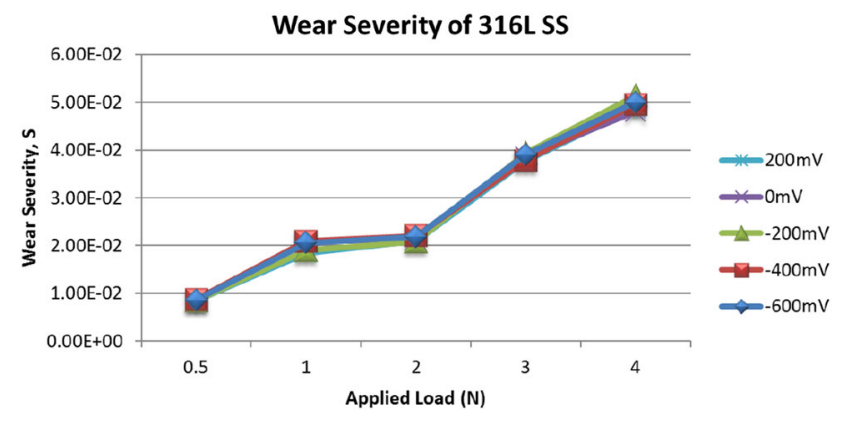

Fig. 13 Wear severity ' $S$ ' for $316 \mathrm{~L}$ SS in artificial saliva 


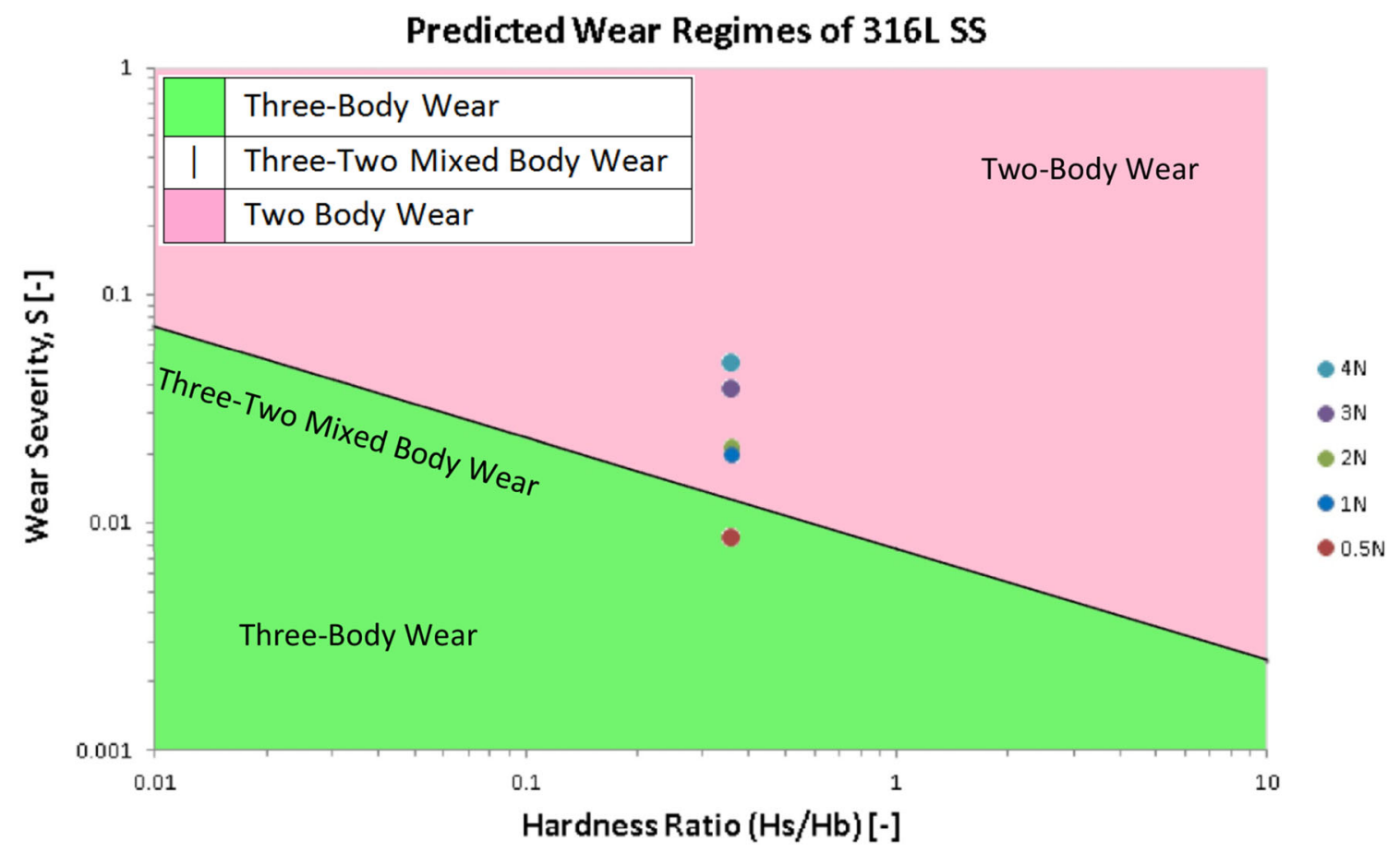

Fig. 14 Predicted wear regimes for 316L SS at different loads
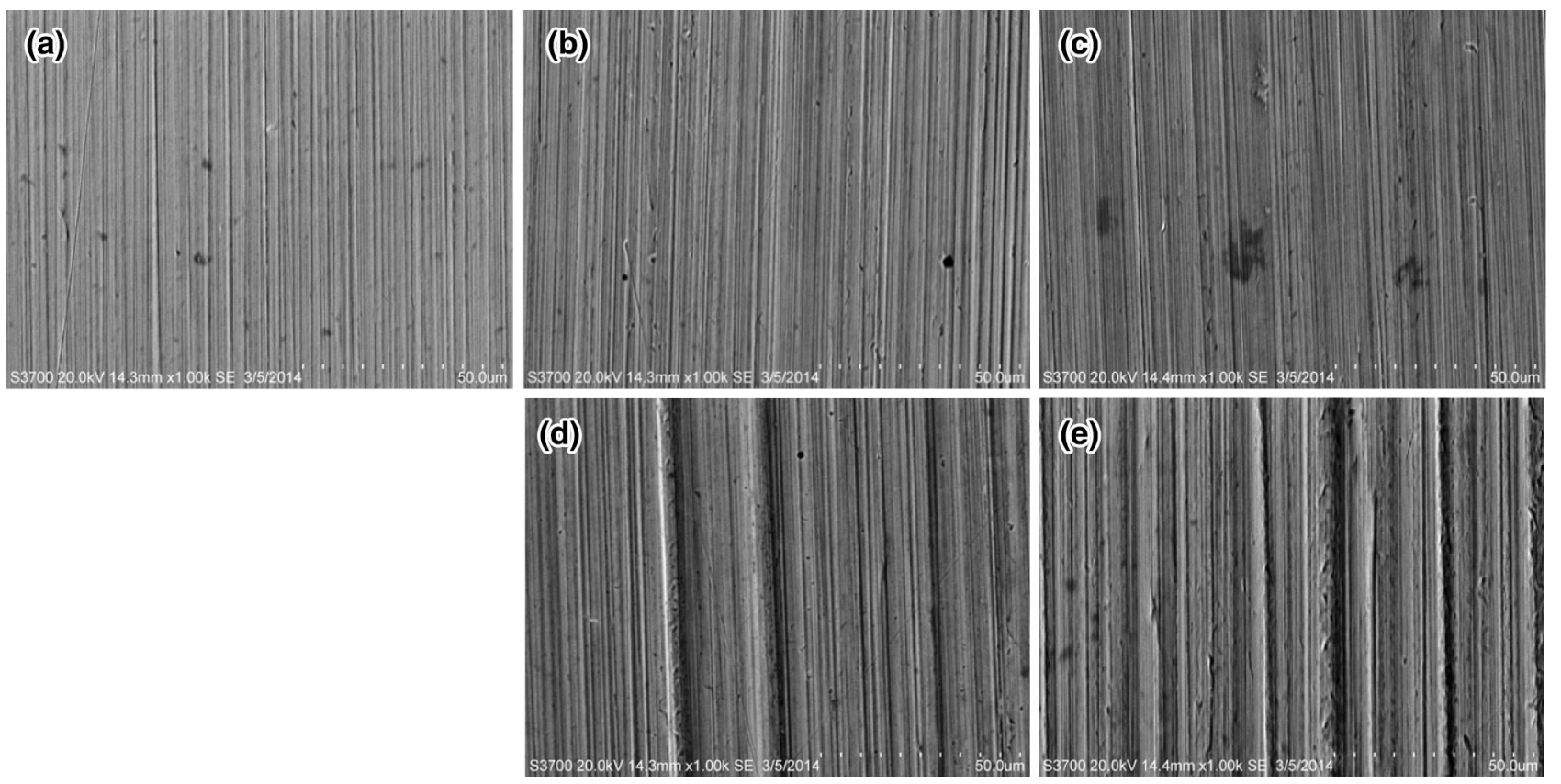

Fig. 15 SEM micrographs of wear scars from the cyclic sweep tests $(\times 1000$ magnification) for a $0.5 \mathrm{~N}$, b $1 \mathrm{~N}$, c $2 \mathrm{~N}, \mathbf{d} 3 \mathrm{~N}$ and e $4 \mathrm{~N}$

wear and then back to a mixture of three- and two-body wear $[22,35]$.

In addition to establishing the calculation for wear severity ' $S$ ', Adachi and Hutchings [26] were also able to quantify the wear severity at which regime transitions occur for a given surface to cratering ball hardness ratio. Based on multiple micro-abrasion test studies of different materials using various abrasive particles and solutions, they proposed that three-body abrasive wear will transition to two-body abrasive wear when 
$S=\frac{W}{A v H^{\prime}}>\alpha\left(\frac{H_{\mathrm{s}}}{H_{\mathrm{b}}}\right)^{\beta}$

Dimensionless constants: $\alpha=0.0076 ; \quad \beta=-0.49$, where the notation is the same as for the severity of wear ' $S$ ' (Eqs. 7-9). The surface to cratering ball hardness ratio for 316L SS and UHMWPE is 0.36 (see Table 3). This means, that according to Adachi and Hutchings' prediction, the wear regime is expected to transition from three to twobody wear at a wear severity value of 0.01254 . The mean wear severity values for each applied load and the transition conditions are plotted in the Fig. 14. According to this prediction, three-body wear should be present at $0.5 \mathrm{~N}$, two-body wear at loads of $1 \mathrm{~N}$ and higher and the possibility of a mixed wear regime at $0.5,1$ and $2 \mathrm{~N}$. Some of these wear regimes can be confirmed by the SEM micrographs of the wear scars (Fig. 15).

The SEM micrographs for $0.5 \mathrm{~N}$ samples show signs of non-directional wear suggesting three-body rolling wear (Fig. 5a). If the magnification of the $0.5 \mathrm{~N}$ micrographs is increased, the signs of directional wear can be observed (Fig. 15a). This is potentially caused by two-body grooving wear indicating a mixed wear regime at $0.5 \mathrm{~N}$. The SEM micrographs for $1 \mathrm{~N}$ samples show a slight increase in twobody grooving wear, but it appeared to still be displaying a mixed regime (Fig. 15b). For samples of $2 \mathrm{~N}$ and higher, very clear two-body grooving can be observed suggesting that by $2 \mathrm{~N}$, the wear regime has fully transitioned to twobody wear (Fig. 15c-e). These micrograph results appear to be consistent with the Adachi and Hutchings prediction for wear regime transition.

\section{Conclusions}

- A study of the effects of applied load and electrical potential on the micro-abrasion-corrosion mechanisms of $316 \mathrm{~L}$ stainless steel in artificial saliva has been carried out.

- The results from the micro-abrasion-corrosion tests were used to generate polarisation curves, wastage and mechanism maps and to describe the material's tribocorrosion behaviour in a simulated oral environment.

- It was found that the corrosion resistant nature of $316 \mathrm{~L}$ stainless steel dominated for all test conditions.

- The superior corrosion resistance of $316 \mathrm{~L}$ stainless steel has resulted in a micro-abrasion rate to be significantly higher than corrosion rate. This was confirmed by the microscopy inspection as any visual signs of surface corrosion had been removed by the micro-abrasion mechanisms which predominate.
- The polarisation curve results displayed a significant increase in corrosion current density in the presence of abrasive particles suggesting the removal of the protective chromium oxide passive film.

- The micro-abrasion and corrosion weight loss results suggest that the rate of corrosion in anodic conditions increases with the increase of micro-abrasion.

- Repassivation phenomena were observed in the polarisation curves with higher micro-abrasion. A higher frequency of repassivation was observed for higher rates of micro-abrasion.

\section{References}

1. Chen J (2014) Food oral processing: Some important underpinning principles of eating and sensory perception. Food Struct 1(2):91-105

2. Mirjalili M, Momeni M, Ebrahimi N, Moayed MH (2013) Comparative study on corrosion behaviour of Nitinol and stainless steel orthodontic wires in simulated saliva solution in presence of fluoride ions. Mater Sci Eng C 33(4):2084-2093

3. Hodge C, Stack MM (2010) Tribo-corrosion mechanisms of stainless steel in soft drinks. Wear 270(1):104-114

4. Kocijan A, Merl DK, Jenko M (2011) The corrosion behaviour of austenitic and duplex stainless steels in artificial saliva with the addition of fluoride. Corros Sci 53(2):776-783

5. Antunes RA, Rodas ACD, Lima NB, Higa OZ, Costa I (2010) Study of the corrosion resistance and in vitro biocompatibility of PVD TiCN-coated AISI 316L austenitic stainless steel for orthopedic applications. Surf Coat Technol 205(7):2074-2081

6. Holmes D, Sharifi S, Stack MM (2014) Tribo-corrosion of steel in artificial saliva. Tribol Int 75:80-86

7. Shen JZ, Tampieri A, Chevalier J, Engqvist H, Ferreira J, Sánchez Vilches E, Bowen P, Krell A, Zhe Z, Wang L, Liu Y, Si W, Feng H, Tao Y, Ma Z (2012) Friction and wear behaviors of dental ceramics against natural tooth enamel. J Eur Ceram Soc 32(11):2599-2606

8. Sun D, Wharton JA, Wood RJK (2009) Micro-abrasion mechanisms of cast CoCrMo in simulated body fluids. Wear 267(11):1845-1855

9. Gocmez H, Tuncer M, Uzulmez I, Sahin O (2012) Particle formation and agglomeration of an alumina-zirconia powder synthesized an supercritical $\mathrm{CO}_{2}$ method. Ceram Int 38(2): $1215-1219$

10. Muthukumaran V, Selladurai V, Nandhakumar S, Senthilkumar M (2010) Experimental investigation on corrosion and hardness of ion implanted AISI 316L stainless steel. Mater Des 31(6): 2813-2817

11. Chen J, Khandelwal N, Liu Z, Funami T (2013) Influences of food hardness on the particle size distribution of food boluses. Arch Oral Biol 58(3):293-298

12. Telfer CG, Stack MM, Jana BD (2012) Particle concentration and size effects on the erosion-corrosion of pure metals in aqueous slurries. Tribol Int 53:35-44

13. Stack MM, Huang W, Wang G, Hodge C (2011) Some views on the construction of bio-tribo-corrosion maps for Titanium alloys in Hank's solution: Particle concentration and applied loads effects. Tribol Int 44(12):1827-1837 
14. Sharifi S, Stack MM (2013) A comparison of the tribological behaviour of Y-TZP in tea and coffee under micro-abrasion conditions. J Phys D 46(40):404008

15. Marcus K, Allen C (1994) The sliding wear of ultrahigh molecular weight polyethylene in an aqueous environment. Wear 178(1-2): 17-28

16. Wong JY, Bronzino JD (2007) Biomaterials. CRC Press, Boca Raton, p 296

17. Trezona RI, Allsopp DN, Hutchings IM (1999) Transitions between two-body and three-body abrasive wear: influence of test conditions in the microscale abrasive wear test. Wear 225-229:205-214

18. Jalabert-Malbos M-L, Mishellany-Dutour A, Woda A, Peyron M-A (2007) Particle size distribution in the food bolus after mastication of natural foods. Food Qual Prefer 18(5):803-812

19. Oshida Y (2013) Bioscience and bioengineering of titanium materials. Elsevier, Amsterdam, pp 35-85

20. Stack MM, Rodling J, Mathew MT, Jawan H, Huang W, Park G, Hodge C (2010) Micro-abrasion-corrosion of a $\mathrm{Co}-\mathrm{Cr} /$ UHMWPE couple in Ringer's solution: an approach to construction of mechanism and synergism maps for application to bio-implants. Wear 269(5):376-382

21. Hutchings I (1992) Tribology, friction and wear of engineering materials. Elsevier Limited, Cambridge, p 284

22. Stack M, Mathew M (2003) Micro-abrasion transitions of metallic materials. Wear 255(1-6):14-22

23. Gee MG, Gant A, Hutchings I, Bethke R, Schiffman K, Van Acker K, Poulat S, Gachon Y, von Stebut J (2003) Progress towards standardisation of ball cratering. Wear 255(1):1-13
24. Lim S (1998) Recent developments in wear-mechanism maps. Tribol Int 31(1):87-97

25. Amini S, Miserez A (2013) Wear and abrasion resistance selection maps of biological materials. Acta Biomater 9(8):7895-7907

26. Adachi K, Hutchings IM (2003) Wear-mode mapping for the micro-scale abrasion test. Wear 255(1):23-29

27. Stack MM, Corlett N, Zhou S (1997) A methodology for the construction of the erosion-corrosion map in aqueous environments. Wear 203-204:474-488

28. Lansdown AR, Price AL (1986) Materials to resist wear (Materials Engineering Practice). Pergamon, p 200

29. Shipway P, Hodge CJ (2000) Microabrasion of glass-the critical role of ridge formation. Wear 237(1):90-97

30. Pourbaix M (1974) Atlas of electrochemical equilibria in aqueous solutions. National Association of Corrosion Engineers, Houston, p 644

31. Johnson SL (2006) Surface studies of potentially corrosion resistant thin film coatings on chromium and type 316L stainless steel. Kansas State University, Manhattan

32. Archard JF (1953) Contact and Rubbing of Flat Surfaces. J Appl Phys 24(8):981

33. Bera B (2013) Adhesive wear theory of micromechanical surface contact. Int J Comput Eng Res 3(3):73-78

34. Camerini RV, de Souza RB, de Carli F, Pereira AS, Balzaretti NM (2011) Ball cratering test on ductile materials. Wear 271(5):770-774

35. Trezona R, Hutchings I (1999) Three-body abrasive wear testing of soft materials. Wear 233:209-221 